\title{
The role of the spatial scale and data accuracy on deep-seated gravitational slope deformation modeling: The Ronco landslide, Italy
}

\author{
Laura Longoni *, Monica Papini, Davide Brambilla, Diego Arosio, Luigi Zanzi
}

Dipartimento di Ingegneria Civile e Ambientale, Politecnico di Milano, Piazza Leonardo da Vinci 32, Milano, Italy

\section{A R T I C L E I N F O}

\section{Article history:}

Received 18 February 2015

Received in revised form 3 September 2015

Accepted 30 September 2015

Available online 3 October 2015

\section{Keywords:}

Spatial scale

Deep-seated gravitational deformations

Large landslide

Numerical modeling

\begin{abstract}
A B S T R A C T
In recent decades numerical models have been developed and extensively used for landslide hazard and risk assessment. The reliability of the outcomes of these numerical simulations must be evaluated carefully as it mainly depends on the soundness of the physical model of the landslide that in turn often requires the integration of several surface and subsurface surveys in order to achieve a satisfactory spatial resolution. Merging diverse sources of data may be particularly complex for large landslides, because of intrinsic heterogeneity and possible great data uncertainty. In this paper, we assess the spatial scale and data accuracy required for effective numerical landslide modeling. We focus on two particular aspects: the model extent and the accuracy of input datasets. The Ronco landslide, a deep-seated gravitational slope deformation (DSGSD) located in the North of Italy, was used as a test-bed. Geological, geomorphological and geophysical data were combined and, as a result, eight models with different spatial scales and data accuracies were obtained. The models were used to run a back analysis of an event in 2002, during which part of the slope moved after intense rainfalls. The results point to the key role of a proper geomorphological zonation to properly set the model extent. The accuracy level of the input datasets should also be tuned. We suggest applying the approach presented here to other DSGSDs with different geological and geomorphological settings to test the reliability of our findings.
\end{abstract}

(C) 2015 Elsevier B.V. All rights reserved.

\section{Introduction}

Large-scale landslides are difficult to study due to the complexity of the involved geological processes and to their intrinsic spatial variability (Tibaldi et al., 2004; Chelli et al., 2006; Moro et al., 2012; Huang, 2012). Landslide analysis can be performed through the use of empirical methods, physical models and numerical models. Numerical simulations are often considered the most promising technique to study slope stability thanks to the developments in computational technology in recent decades, including the improved performance of numerical software. On the other hand, numerical simulations require detailed input datasets, which are often difficult to collect, and merging collected data to create a synthetic model is challenging. Therefore, despite their success (Dymond and De Rose, 2011), numerical models should only be used when available input data include all the relevant features to provide accurate outcomes. Generally, numerical models are aimed at: i) predicting the kinematics of the slope movements (Huang et al., 2009; Ning et al., 2011; Longoni et al., 2014); and ii) forecasting the triggering factors that may lead to failure (Della Seta et al., 2013; Camera et al., 2014). If available data are not sufficient to achieve these goals, numerical modeling is unprofitable (Goodchild, 2011).

\footnotetext{
* Corresponding author.

E-mail address: laura.longoni@polimi.it (L. Longoni).
}

The key point for performing efficient numerical simulations lies in the definition of geometric and geo-mechanical features of the physical model in relation to the spatial scale (Longoni et al., 2012). The choice of the spatial scale of the physical model must be carefully considered. The role of scale in geomorphology has been massively debated (Warke and McKinley, 2011): some considered the spatial scale (Zhang et al., 2011; Kerry and Oliver, 2011; Yan et al., 2011), some addressed the temporal scale (Smith, 1996; Viles, 2001; Dymond and De Rose, 2011) and others focused on how to upscale observations from microscale to macroscale (Viles and Moses, 1998; Viles, 2001; Zengchao et al., 2009). In terms of the scale choice, we acknowledge the statement by Schumm and Lichty (1965): "As the dimensions of time and space change, cause-effect relationships may be obscured or even reversed, and the system itself may be described differently", and that by Bachmann et al. (2006): "a single landslide $[. .$.$] evolution will depend on what is happening at larger but$ also at smaller scales". Accordingly, this paper focuses on the effect of the spatial scale and data accuracy on landslide modeling for failure forecasting. Although numerical simulations are widely employed for landslide evaluation, limited efforts have been made to critically compare the results with different spatial scales and data accuracies.

The Ronco landslide in Italy, a deep-seated gravitational slope deformation (DSGSD), is investigated as a case study. Though the analysis is site-specific, the proposed method may be useful for other large landslides. This paper starts with the description of the Ronco landslide, which reactivated after intense rainfalls in November 2002. After that 
event, many investigations were performed based on geophysical, geomorphological and geological surveys. As a consequence, high quality data were collected and a detailed database of the landslide features was generated. We took advantage of this situation. This work aims to understand the spatial scale and accuracy required to foresee the behavior of a large landslide, and the 2002 event is used for a back analysis to define the arrangements to replicate slope behavior. First, we consider whether a global overview of the landslide is better than a local focus on the most dangerous area. Second, the accuracy of input data is discussed to define how improvements in slope characterization affects landslide modeling. The high costs of detailed investigations often prevent a complete characterization of large landslides. Therefore, numerical simulations of large landslides are usually theoretical or dedicated to representative cases. In many instances, only data for a few parameters are available; thus it is important to understand the required data accuracy level to obtain meaningful outcomes.

\section{Geological setting of the case study}

Many large-scale landslides are mapped in the North of Italy. The Vajont landslide (Kilburn and Petley, 2003; Panizzo et al., 2005) and the Val Pola landslides (Crosta et al., 2004; Pirulli and Mangeney, 2008) are well-known examples, and many other slopes are affected by such phenomena. The Bindo landslide (Crosta et al., 2006), Mount Letè and Mount Legnoncino landslides (Ambrosi and Crosta, 2006), and the Ruinon landslide (Agliardi et al., 2001; Del Ventisette et al., 2012) are just a few examples near the investigated Ronco landslide.

The Ronco Landslide is a DSGSD located closed to Premana, a small village in Varrone Valley $100 \mathrm{~km}$ North of Milan (Fig. 1). The landslide directly threatens a hydroelectric power plant and the probability that the landslide body could occlude the riverbed creating a natural dam is very high, since The Valley is very narrow close to the plant. If a dam is created, the entire upstream industrial district of Premana would be flooded (Fig. 1), while the risk of a dam break would pose a threat for the Pagnona Dam, less than a kilometer downstream, as well as Dervio City, where the Varrone River flows into Como Lake (Arosio et al., 2011). Additionally, a total reactivation of the DSGSD body may also generate direct damage to Premana Village. During a heavy rainfall event in 2002, slope displacements were recorded in the area near the hydroelectric power plant. After this partial reactivation of the landslide, it was decided to investigate the unstable slope.

The deep-seated landslide affects the entire slope (Fig. 1): the crown is located near the Paglio peak and the toe of the landslide is at $750 \mathrm{~m}$ a.s.l. at the bottom of Varrone Valley. Three geological units can be identified: Gneiss Chiari, Servino and Verrucano Lombardo (Fig. 2). The most important tectonic lineament of the investigated area is the Orobic
Thrust (Fig. 3) (Schönborn, 1992; Blom and Passchier, 1997), where the crystalline basement (Gneiss Chiari) overthrusts the sedimentary cover (Verrucano Lombardo and Servino) as depicted in Fig. 2b. A plastic layer, hereafter named tectonic mélange, lies between the Gneiss Chiari and Servino formations. This layer has variable thickness ranging from 5 to $20 \mathrm{~m}$ and consists of severely deformed and altered carniole, a rock originated from the tectonization of the formations in contact. The tectonic mélange layer is generally considered a discontinuity that may act as a sliding surface within unstable slopes, as several slope failures have occurred because of such layers in northern Italy (e.g. ramp-flat of the Grigna Group in the pre-Alpine region, northern Italy; Jadoul and Gaetani, 1986).

Close to Premana Village, the Orobic Thrust has dip and dip direction of approximately $15^{\circ}$ and $330^{\circ}$ respectively, and outcrops near the hydroelectric power plant. The slope also features two sets of minor faults: the first one has an N-S strike and a dip of $80^{\circ}$, and the other has an ENE-WSW strike and a dip of $75^{\circ}$. The latter has $500 \mathrm{~m}$ spacing and is related to the Orobic Thrust as well as to the Alpine orogenesis processes, while the $\mathrm{N}-\mathrm{S}$ faults, where spacing spanning between 100 and $300 \mathrm{~m}$, were generated by older processes (Late Triassic) and acted as discontinuity surfaces during the Alpine orogenesis (Forcella and Rossi, 1987). A large bulged section across Piani di Ronco (i.e., the flat area located in the middle of the DSGSD; Fig. 1), together with an evident line associated with the DSGSD main scarp - probably generated by glacier debuttressing processes - are geomorphological evidences related to the instability of the slope (Fig. 3). The exceptional rainfalls in November 2002 caused the reactivation of the lowest section of the ancient deep-seated landslide and, based upon the damages to the hydroelectric power plant and the bridge located at the toe of the slope, the Ronco landslide seems to have moved approximately $30 \mathrm{~cm}$ during that event (Savazzi, 2005). The complexity of the geological setting (Fig. 3 ) and the high risk associated with this unstable slope required detailed investigations to outline the main features of the slope. Hence several survey techniques (Table 1 ) were employed to better characterize the rock mass (Arosio et al., 2011, 2013). As reported in Table 1, the borehole constructed in 2003 did not reach the Orobic thrust, the depth of which, based on the borehole made in 2012, is at about $120 \mathrm{~m}$.

\section{Geomorphological assessment}

The studied area underwent the deposition of thick glacial deposits on both the valley bottom and valley flanks in the Pleistocene. During the Holocene the valley was modified because the erosion of the Varrone River deepened the valley bottom (Fig. 4). Widespread and thick landslide debris over the glacial deposits suggests that significant collapses occurred on the slope below the Paglio Peak, which were
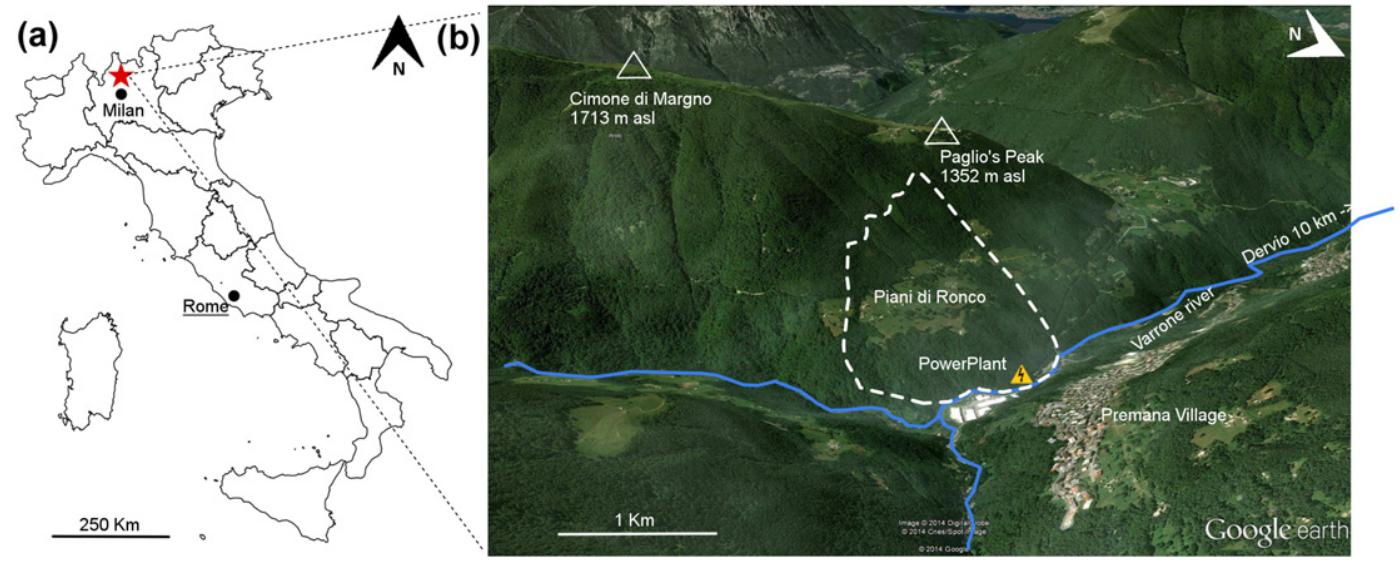

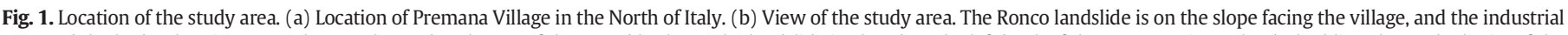

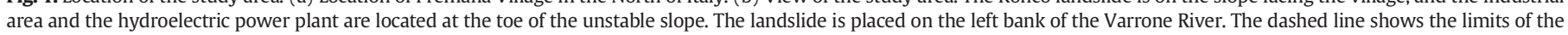
DSGSD body. 

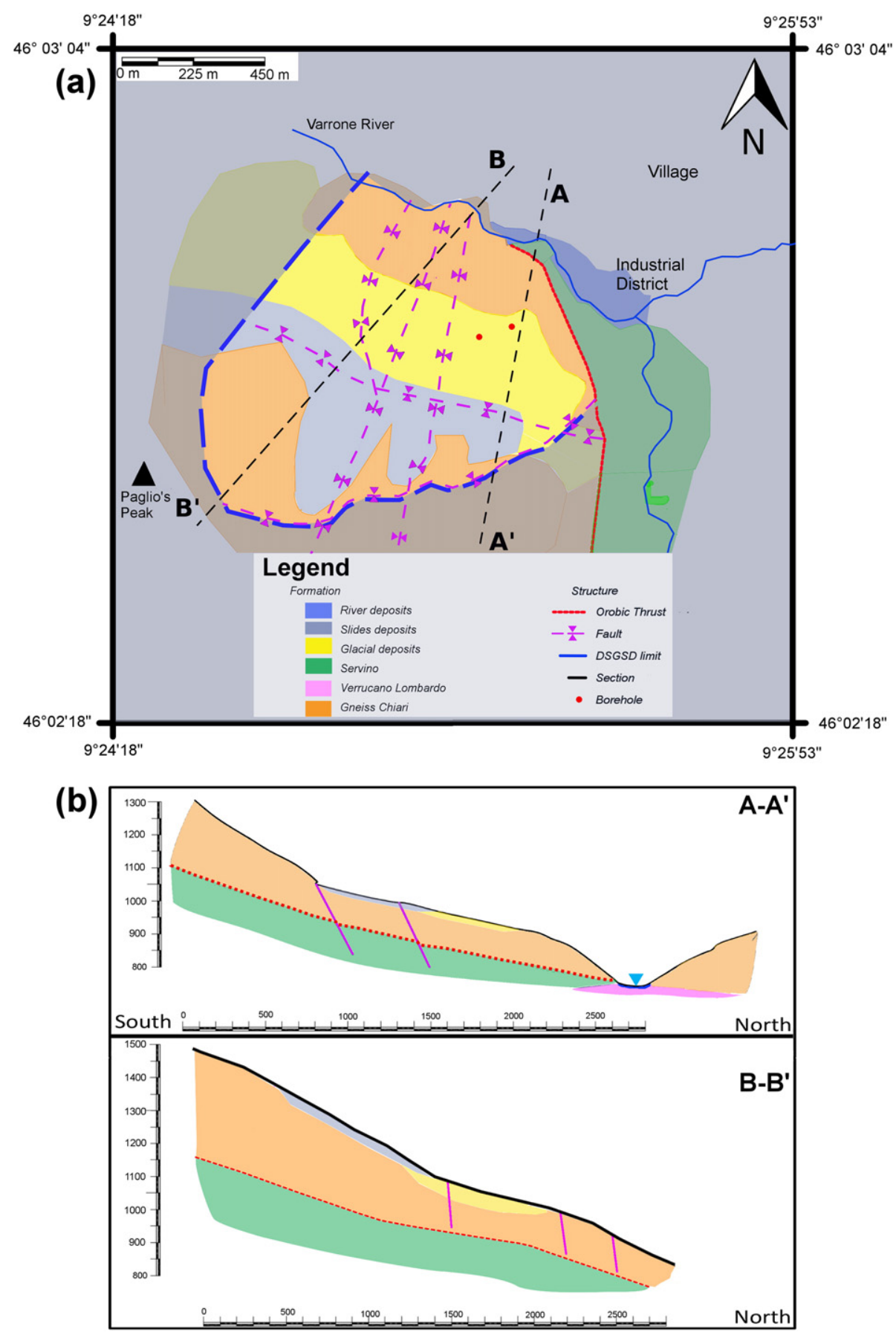

Fig. 2. Geological setting of the Ronco landslide. (a) Geological map. (b) Geological sections.

probably triggered by glacial melting and the subsequent slope debuttressing (Fig. 4). Hence, the present geomorphological setting can be explained as the result of the following sequence of events:

A. Glacier formation and U-shaping of the ancient valley with glacial erosion and debris deposition, mainly during the Last Glacial Maximum;

B. Final retreat of glaciers, slope debuttressing, DSGSDs initiation along plastic layers (carniole) and slope gravitational collapses;

C. Concurrent and gradual transition from a glacial climate to periglacial conditions that promoted the shaping of landslide debris because of rock flow phenomena; and

D. Erosion due to the Varrone River and resulting valley deepening.
These processes occurred during the Holocene and created outcrops of the Orobic thrust and the underlying sedimentary succession.

Landslide debris material indicates that river erosion at the toe of the slope triggered several collapses along the flanks of the V-shaped river valley immediately below the Piani di Ronco (Fig. 4). These mass movements are undoubtedly more recent than those related to glacial debuttressing, because they relate to slopes created by river erosion in the Holocene.

In summary, the geomorphological analysis clearly shows that the slope is affected by an ancient DSGSD dating back to the Pleistocene, the eastern section of which was reactivated because of river erosion at the slope toe during the Holocene. The main discontinuities across 


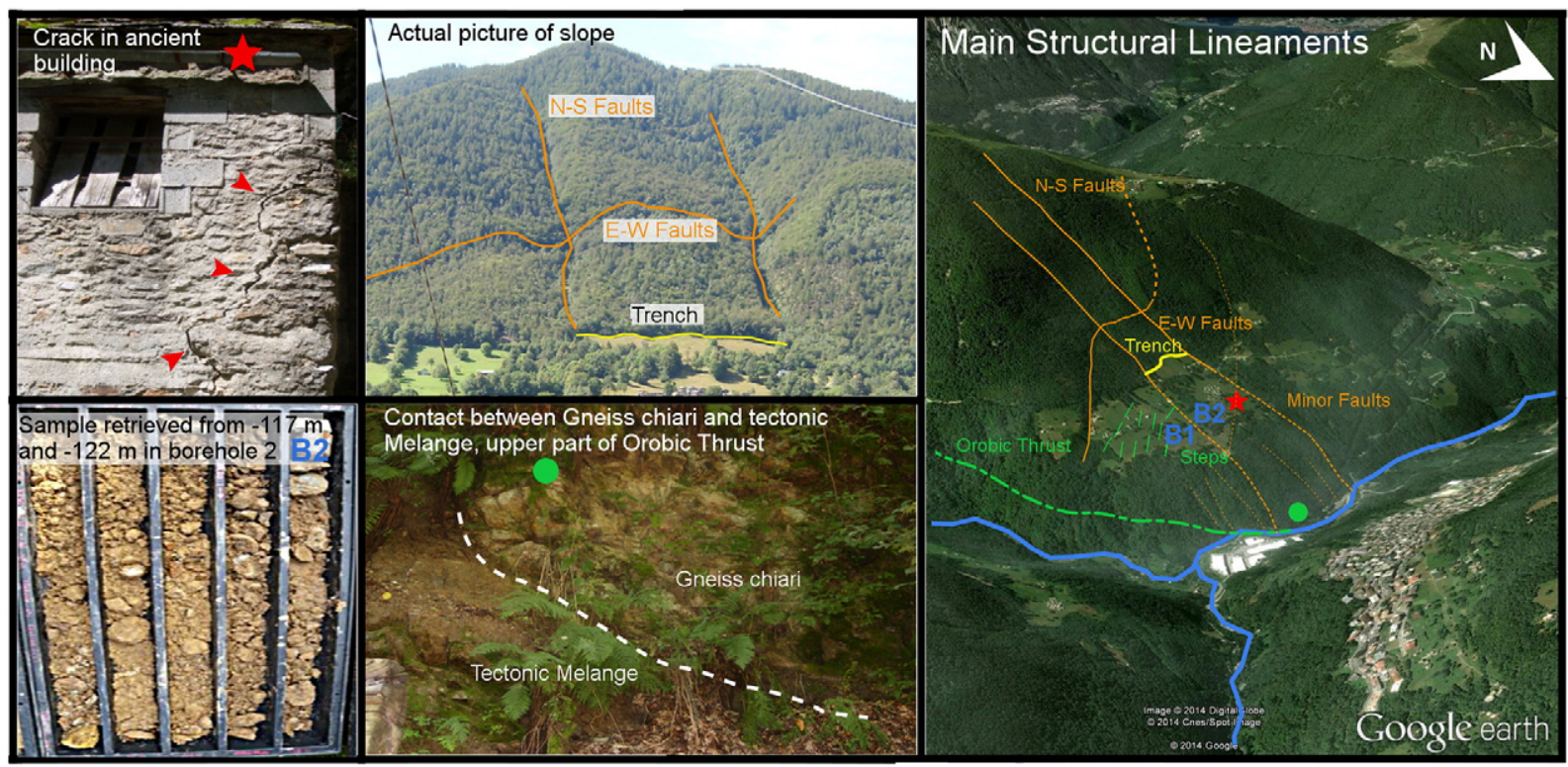

Fig. 3. Photographs associated with the Ronco landslide.

the slope delineate an unstable body consisting of Gneiss Chiari rock. More specifically, the movement and deformation of the slope are controlled by the tectonic lineaments, namely the Orobic Thrust and two fault sets having N-S and ENE-WSW directions. Recent slope movements are being triggered by unusually heavy rainfalls, as demonstrated by the reactivation of the lowest section of the ancient deep-seated landslide in November 2002.

\section{The spatial scale and data accuracy for numerical simulations}

The complex problem of spatial resolution is evaluated according to two different aspects, with the first one being the model extent. Usually it is easier and more effective to focus on the features of a limited area of the landslide body to develop a local model describing the most dangerous area of the unstable slope (Lebourg et al., 2005; Crosta et al., 2006; Casagli et al., 2010; Marcato et al., 2012). Alternatively, a global view of the whole slope is sometimes preferred to evaluate the potential influence of all features on the mass movement (Agliardi et al., 2001; Apuani et al., 2007; Brideau et al., 2011). The second aspect is the accuracy of the analysis that mainly depends on the quantity of available data. This is obviously a key point for physical model construction: more information will help to generate a model that is closer to reality.

For the aim of this paper, several synthetic models with different spatial scales and accuracies were generated. The geomorphological investigations that were performed helped us to understand the past geological processes that affected the slope and locate the most dangerous areas prone to instability. The outcomes of the previous assessment were used to establish the extent of the models for the numerical analysis, and both global and local models were defined (Fig. 5). The global model includes virtually the whole DSGSD as it is delimited by the major tectonic lineaments along N-S and ENE-WSW directions, and by the Orobic Thrust at the bottom. The local model takes into account a limited part of the DSGSD as it involves just the most unstable part of the slope that was activated during the 2002 rainfall event. The western boundary of the model is an N-S fault, while the east boundary is the DSGSD west flank. The E-W fault on Piani di Ronco is considered the southern limit of the model. Transverse fractures with lengths varying from a few meters to tens of meters were found along this fault after the 2002 event. The depth is again constrained by the tectonic mélange at the point of contact between the Gneiss Chiari and Servino formations.

Four levels of accuracy were considered:

i) Level 1 (low accuracy): Widely available general data. In our study a 1:25,000 geological map.

ii) Level 2 (basic accuracy): Information of Level 1 has been verified and improved through field analysis. Geological mapping was performed across the entire slope to define the boundary of the most dangerous area.

iii) Level 3 (good accuracy): Information of Level 2 has been improved by means of several laboratory and field investigations.

iv) Level 4 (high accuracy): Information of Level 3 has been improved through additional specific investigations.

The combination of two different modeling extents (global and local) and the four accuracy levels yields eight synthetic models, the

Table 1

Field and laboratory investigations performed at Ronco Landslide since 2003.

\begin{tabular}{|c|c|c|c|}
\hline Survey technique & Location & Objective & Year \\
\hline Borehole $(90 \mathrm{~m})$ & Piani di Ronco & $\begin{array}{l}\text { Orobic thrust analysis (not accomplished) } \\
\text { Gneiss Chiari geomechanical properties (RQD) } \\
\text { Characterization of layers }\end{array}$ & 2003 \\
\hline Piezometer & Piani di Ronco & Monitoring of the groundwater table level & 2003 \\
\hline Borehole and inclinometer & Landslide toe & Monitoring deep movements at the base of the slope & 2003 \\
\hline Laboratory tests & Specimens from borehole made in 2003 & Geomechanical characterization of Gneiss (UCS, cohesion, Friction angle) & 2004 \\
\hline Electrical resistivity tomography & Piani di Ronco & Groundwater table analysis & 2004 \\
\hline GPR (Ground Penetrating Radar) investigation & Piani di Ronco & Detection of fractures in the near subsurface & 2010 \\
\hline Refraction seismic survey & Piani di Ronco & Characterization of layers (thickness and velocity of P and S waves) & 2011 \\
\hline MASW (Multichannel Analysis of Surface Waves) & Piani di Ronco & Characterization of layers (thickness and velocity of S wave) & 2011 \\
\hline Borehole $(120 \mathrm{~m})$ & Piani di Ronco & $\begin{array}{l}\text { Orobic thrust analysis (accomplished) } \\
\text { Gneiss Chiari geomechanical properties (RQD) }\end{array}$ & 2012 \\
\hline
\end{tabular}




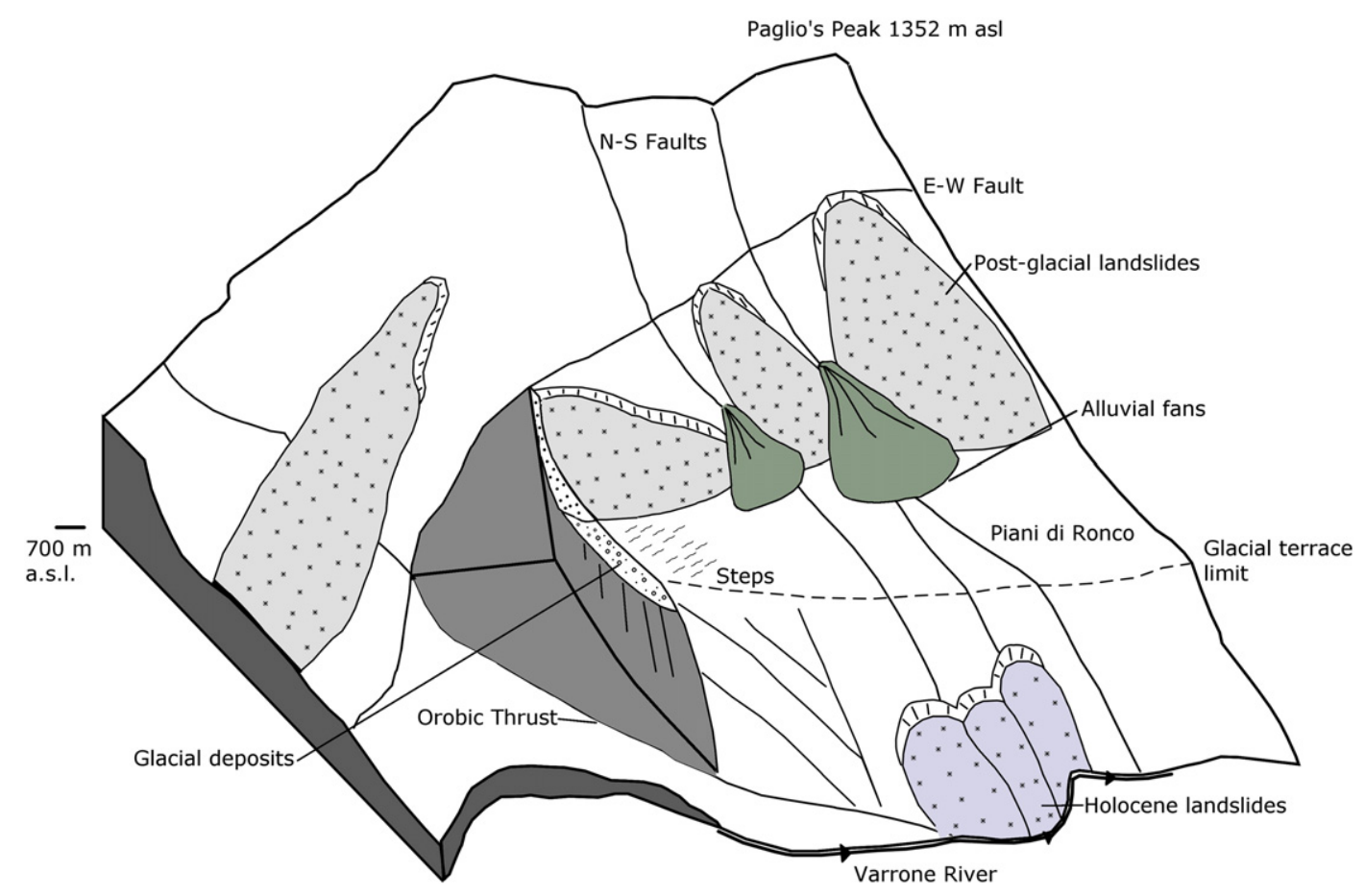

Fig. 4. Geomorphological 3D illustration of the Ronco landslide.

reliability of which was investigated with the help of a three-dimensional distinct element code 3DEC (Itasca, 2007). For each model, a back analysis of the 2002 event was carried out with the piezometric water table representing the hydrogeological conditions of that event.

The rock mass properties and the geometric features of the landslide were defined on the basis of the available investigation results. For the first level of accuracy, the general geological map and geomorphologic evidence allow us to define the geological units, the Orobic Thrust, one of the ENE-WSW faults and one of the N-S faults. Since no other information is available, some parameters were assumed to perform numerical simulations. The Orobic Thrust was considered sub-horizontal and the N-S and ENE-WSW faults were assumed to be vertical, like the main tectonic faults in the Alpine and Pre-Alpine areas. For geomechanical features, RocLab software (Rocscience, 2007) was

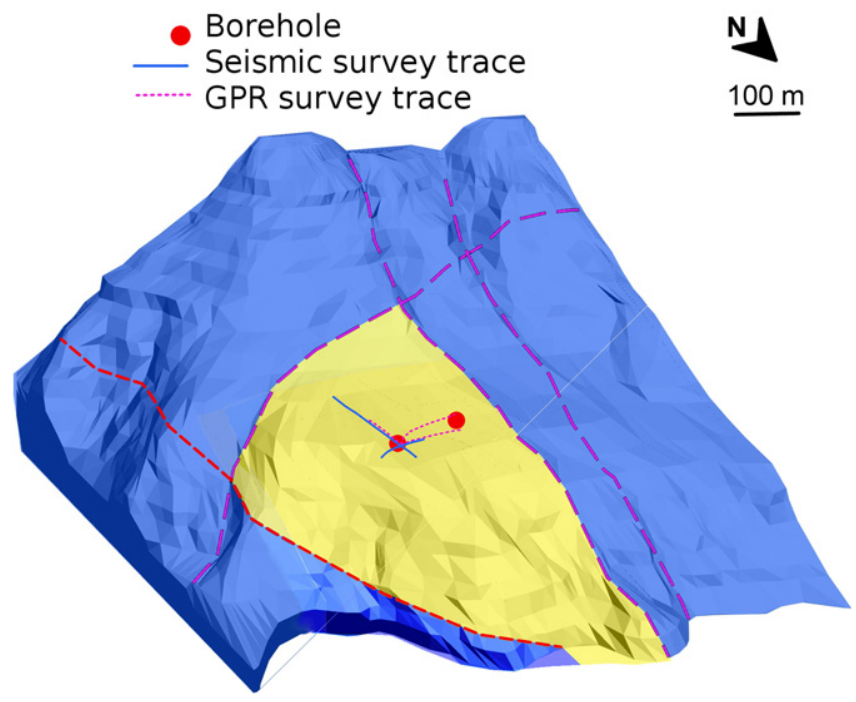

Fig. 5. Boundaries of the tested models: yellow area outlines the local model; and blue area indicates the global model of the Ronco landslide. used. As this requires some basic input information like the geological strength index (GSI), unconfined compressive strength (UCS) and intact rock parameter mi (Hoek and Brown, 1997), average values were derived from the scientific literature: GSI from Marinos and Hoek (2000), and UCS and mi from Hoek et al. (1998). The second level of investigation encompassed field analysis. Thanks to the geological and geomorphological surveys, we were able to identify all faults (Fig. 3) and define a realistic value for the GSI, although a few small outcrops allowed us to estimate the average GSI values for Servino and Gneiss Chiari. In addition, field analysis near the hydroelectric power plant improved the knowledge of the Orobic Thrust that is characterized by the presence of a tectonic mélange with poor geomechanical properties (Fig. 3). The role of this layer of cataclastic rock - the geomechanical features of which were again characterized using RocLab - could be very important in numerical modeling in terms of obtaining reliable outcomes. As far as the third accuracy level is concerned, further datasets were provided by many investigations: borehole analysis, piezometer and inclinometer readings, laboratory tests, electrical resistivity tomography and seismic refraction surveys. Samples collected during coring were used to perform different laboratory tests in which the Servino and Gneiss Chiari faults and the Orobic Thrust were analyzed. One of the main improvements lies in the identification of a severely fractured Gneiss Chiari zone, located in the most dangerous area, where displacements occurred after the 2002 rainfall event. The highest level of accuracy (4th level) was obtained through the integration of all the previous investigations with Ground Penetrating Radar (GPR) and Multichannel Analysis of Surface Waves (MASW) surveys, allowing us to better characterize the most fractured area mentioned above. For accuracy levels 1, 2 and 3, an equivalent model was considered because the available information did not permit us to explicitly model the joint sets. Field investigations and analysis of borehole samples -performed in levels 2 and 3 respectively- allowed us to identify only the most significant discontinuities, but further analysis was necessary to carefully track the orientation of these joints in the subsurface (Lin and Ku, 2005). Particularly, GPR was useful to detect the presence of shallow joint sets that were included in the accuracy level 4 .

For each of the eight model, a back analysis of the 2002 event was carried out (Figs. 6 and 7). 


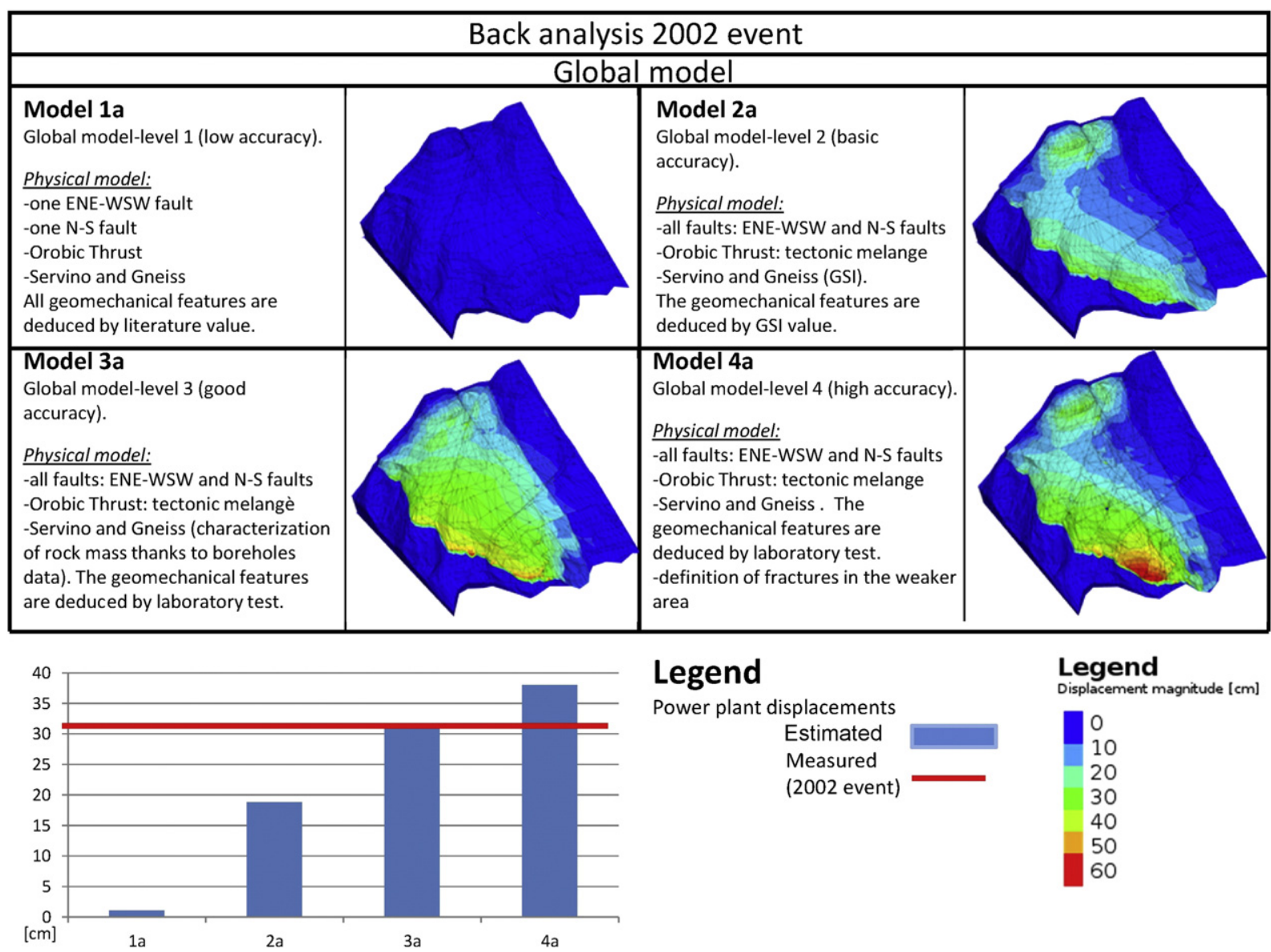

Fig. 6. Back analysis using the global model. Model 3a provides the best results in terms of modeled displacements.

The outcomes of numerical modeling were compared with the displacement data recorded during the 2002 event, and some checkpoints were used to test the performance of the models. One point was located near the hydroelectric power plant, where the presence of some cracks in retaining walls allowed the determination of displacements (about $30 \mathrm{~cm}$; Savazzi, 2005). Other points were placed in the middle part of the slope where some displacements were detected from geomorphological evidence and some damage to houses in Piani di Ronco. By comparing synthetic and real displacements, model 3a provides the best matching (Fig. 6).

\section{Discussion}

Since landslide risk management generally requires tools that can forecast slope behavior, many authors usually address monitoring systems and focus on their capability to track landslide evolution (Pieraccini et al., 2002; Intrieri et al., 2013; Mazzanti et al., 2015). However, limited efforts have been made to properly study the spatial scale and accuracy of slope physical models for effective landslide numerical analysis. The numerical model may be evaluated in terms of its ability to locate the most unstable area of the slope and estimate the magnitude of involved displacements.

The results of the back analysis of the 2002 event can be summarized as follows:

- Both local and global models, except those with low accuracy level, are able to constrain the area most prone to instability;

- The global models (Fig. 6) show that displacement increases in linear fashion with increasing accuracy, whereas, for local models (Fig. 7), a significantly high displacement is obtained only for the high accuracy level.
- Global models offer a complete picture of the mass movement and reveal the relationship between displacements observed at various scales (Bachmann et al., 2006). According to Figs. 6 and 7, the global models present larger displacements and display a common behavior, except in models with a low accuracy - where shallow displacements show a growing trend from Piani di Ronco to the Hydroelectric Power Plant. The displacements in the upper section are related to the ones in the lower section and they should be considered as two components of the same phenomenon (Brideau et al., 2011). Instead, the results from the local models are more complex and lack a single clear trend.

- Joints in the bedrock seem to be vital to correctly describe the behavior of large DSGSDs (Agliardi et al., 2001). Significant improvements are observed when model 1 (low accuracy) is upgraded to model 2 (basic accuracy), especially for the global extent. This is mainly due to the identification of faults and the tectonic mélange layer. Therefore, among various data, the pre-existing structures (Orobic thrust and all faults) may be significant features for comprehending the DSGSD.

- For the global models, high accuracy is not as useful because the associated model (4a, Fig. 6) is not able to improve the outcomes of numerical simulations; conversely, the local extent shows that a comprehensive and detailed dataset leads to a satisfactory numerical simulation (4b, Fig. 7). This point is crucial and further analysis must be done to define which data are necessary to provide a robust description of the mass movement. Our findings suggest that a high accuracy level is more suitable for small-scale models, while an equivalent model may be preferred for global analyses. This seems to agree with the observation by Schumm and Lichty (1965) that a change in space dimension (i.e. model extent) requires a different model description.

Despite these differences, both model extents can provide a good matching between simulated and recorded displacements (3a and 4b - Figs. 6 and 7). However, more analyses are required to thoroughly 


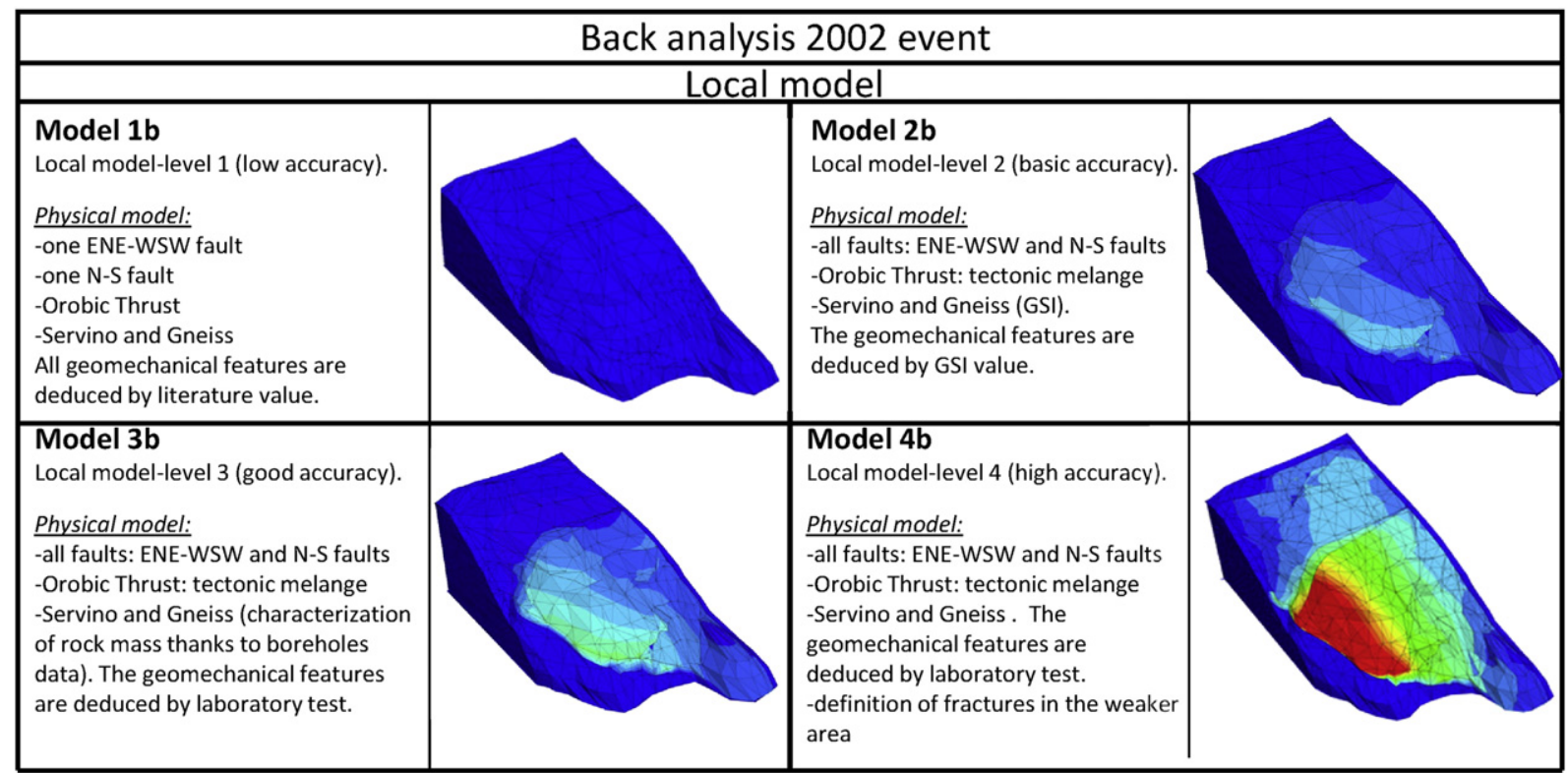

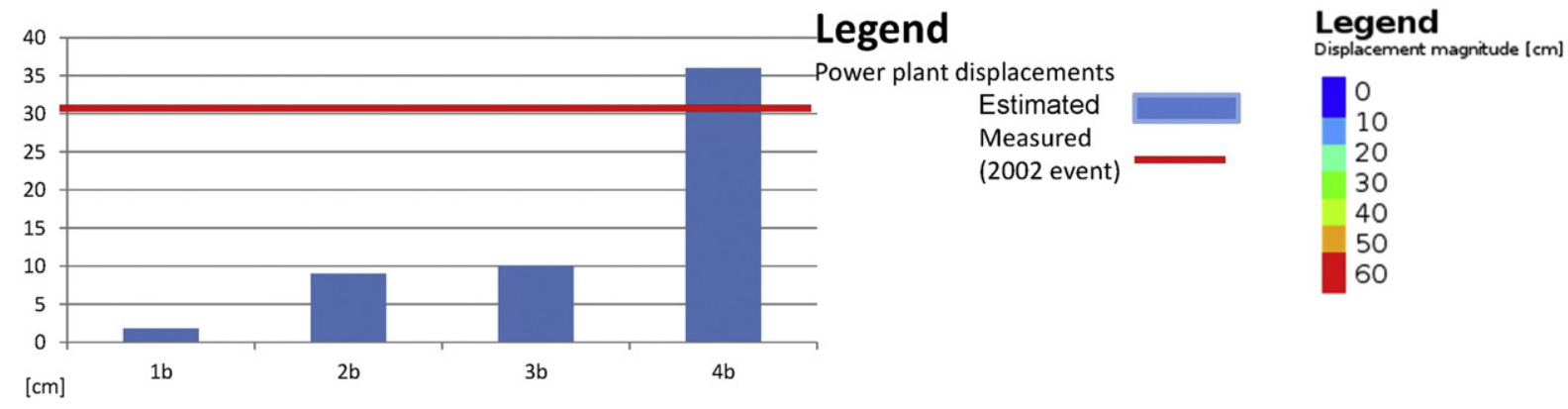

Fig. 7. Back analysis using the local model. Model $4 \mathrm{~b}$ provides the best results in terms of modeled displacements.
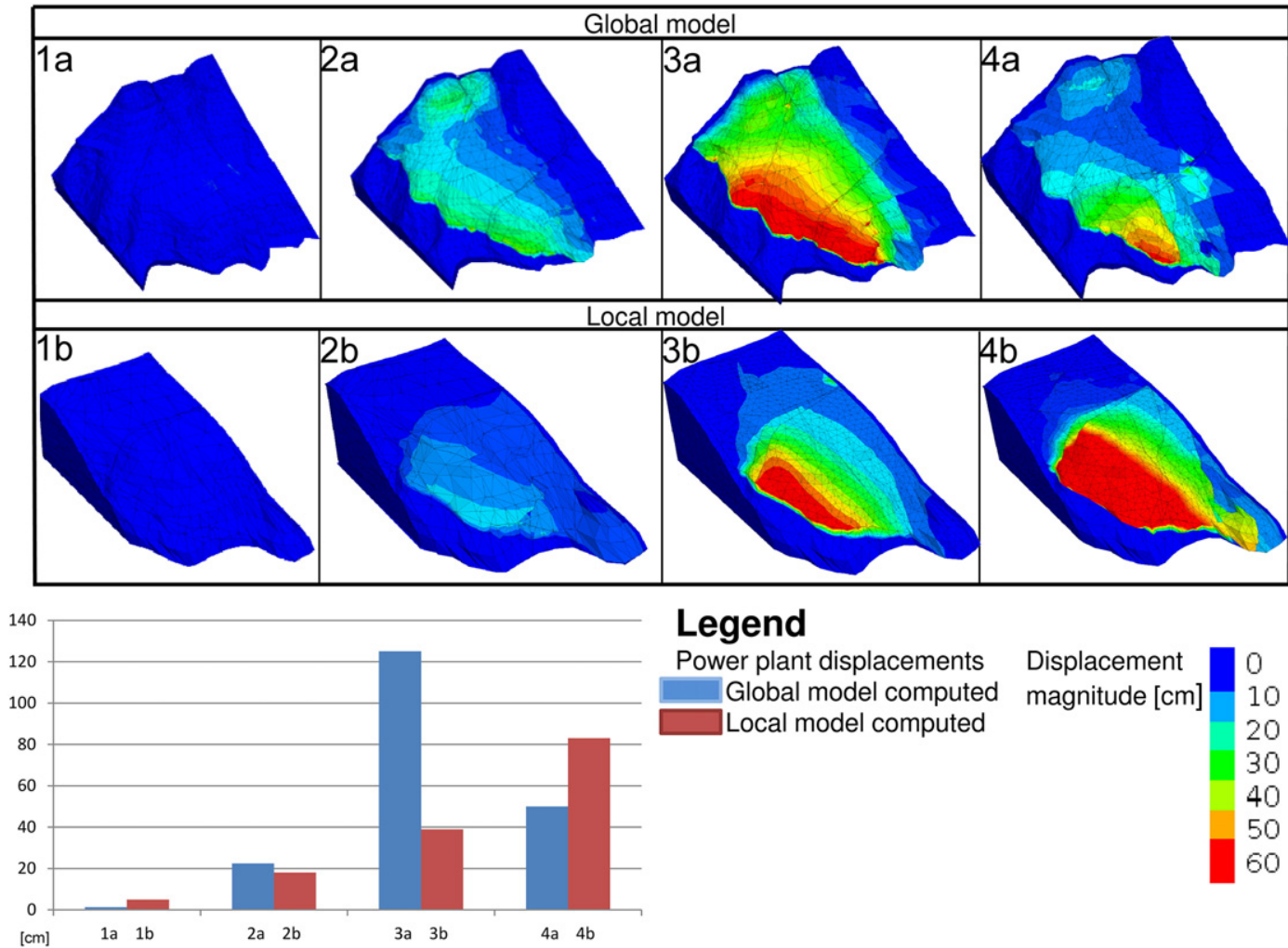

Fig. 8. Numerical simulations with a higher groundwater table level. 
evaluate the influence of the spatial scale and data accuracy on effective modeling. For instance, the cause-effect relationship varies and requires different data accuracies and spatial scales (Schumm and Lichty, 1965). Hence, the role of different triggering factors should be examined. A change in the triggering factors is of great importance for large landslides like DSGSDs, since it may cause the failure of other slope sections and generate different kinematic mechanisms. Therefore, we performed additional simulations in which the groundwater table level was increased to test the response of the models with a different piezometric condition. Fig. 8 shows the results for both modeling extents and the four accuracy levels.

Some considerations on the outcomes are:

- All models except low accuracy ones locate the most unstable area in the N-NE part of the slope, near the hydroelectric power plant.

- Displacements are larger than the ones modeled for the back analysis of the 2002 event. Simulations with the global model show that a displacement peak in the case of a good level of accuracy is difficult to explain without the support of field data. A possible cause may be related to the different discretization of the models. Indeed, the global model with high accuracy (4a) takes account of the joint sets and, as a consequence, the slope is subdivided into several blocks featuring more degrees of freedom. This explanation may be validated from the spatial distribution of displacements (Fig. 8). The equivalent model 3a shows a consistent movement trend with the most dangerous area close to the hydroelectric power plant, while model 4a seems to suggest more complex interactions between the blocks. Discretization may also rule displacement magnitudes: when considered, joint sets mostly control the deformations of the model, while the displacements in an equivalent model are controlled by the deformations of the blocks.

A comparison with real data was impossible because the new piezometric level was assumed just to test the response of the models. Nevertheless, some similarities are found between the back analysis and these new simulations. Both cases show that the most critical area is located in the N-NE part of the slope and highlight the role of structural control in the model response.

\section{Conclusions}

Many landslides are the most active sections of larger unstable slopes that may be referred to as DSGSDs. These mass movements may be very complex and require detailed geological and geomorphological analysis with an accurate monitoring system if available, to define the appropriate spatial scale and data accuracy of a numerical model for analyzing their kinematic behavior. These landslides are often studied through the use of numerical algorithms to generate risk scenarios or understand the triggering factors of slope failure. Nonetheless, the outcomes may be strongly influenced by the spatial resolution of the physical model. Therefore, model parameters are to be tuned carefully. General guidelines to define the spatial scale and data accuracy required for a numerical simulation of a large landslide like a DSGSD have not been established yet. Thus, taking advantage of a rich survey database regarding a DSGSD in northern Italy, we attempted to improve the understanding on how different spatial scales and data accuracies affect the modeling of a large landslide. Starting from a geological and geomorphological analysis, we compared eight models with different features to identify the best arrangement that can reproduce the slope movements during a heavy rainfall event in 2002. Further simulations were carried out to evaluate the response of the models to change in a possible triggering factor.

The back analysis of the 2002 event suggests that the kinematics of the most active area is closely related to the global behavior of the whole slope. Therefore, if the analysis is aimed at evaluating the active processes and the relationship between them, the global model offers a more complete view of the mass movement. Nevertheless, if the boundaries of a local model are defined considering a proper geomorphological zonation, the model can also accurately simulate the real slope behavior.

This work reveals that a numerical analysis with a proper characterization of structural elements is capable of tracking the DSGSD behavior. Recently, Crosta et al. (2014) simulated the behavior of a large landslide within a DSGSD (the Mont de La Saxe rockslide) based on a subdivision of the slope into different zones and their geotechnical characterization for a reliable simulation of the rockslide. These results indicate the need for a complete understanding of active geological processes before performing any numerical analysis. The application of the approach presented here to other DSGSDs with different geological and geomorphological settings is necessary to test the reliability of the approach. Since extensive investigations are required to gather a comprehensive datasets, cost restrictions must be also taken into account.

\section{Acknowledgments}

The authors wish to thank Dr. G. Savazzi who made several investigations on the available datasets for the study area. We are grateful to two anonymous reviewers and to the editor for their comments and suggestions that significantly improved the quality of this paper.

\section{References}

Agliardi, F., Crosta, G.B., Zanchi, A., 2001. Structural constraints on deep-seated slope deformation kinematics. Eng. Geol. 59, 83-102.

Ambrosi, C., Crosta, G.B., 2006. Large sackung along major tectonic features in the Central Italian Alps. Eng. Geol. 83, 183-200.

Apuani, T., Masetti, M., Rossi, M., 2007. Stress-strain-time numerical modelling of a deepseated gravitational slope deformation: preliminary results. Quatern. Int. 171172(0), 80-89

Arosio, D., Brambilla, D., Longoni, L., Papini, M., Savazzi, G., Zanzi, L., 2011. Integration of geological and geophysical data to improve the understanding of a deep-seated landslide. 24th Symposium on the Application of Geophysics to Environmental and Engineering Problems (SAGEEP), Charleston, South Carolina, USA, p. 166.

Arosio, D., Brambilla, D., Longoni, L., Papini, M., Zanzi, L., 2013. New investigations to update the model of the Premana (LC) landslide. Landslide Sci Pract. 6, 755-760.

Bachmann, D., Bouissou, S., Chemenda, A., 2006. Influence of large scale topography on gravitational rock mass movements: new insights from physical modeling. Geophysical Research Letters 33, L21406http://dx.doi.org/10.1029/2006GL028028.

Blom, J.C., Passchier, C.W., 1997. Structures along the Orobic thrust, Central Orobic Alps, Italy. Geol. Rundsch. 86, 627-636.

Brideau, M., Pedrazzini, A., Stead, D., Froese, C., Jaboyedoff, M., van Zeyl, D., 2011. Threedimensional slope stability analysis of South Peak, Crowsnest Pass, Alberta, Canada. Landslides 8, 139-158.

Camera, C.A.S., Apuani, T., Masetti, M., 2014. Mechanisms of failure on terraced slopes: the Valtellina case (northern Italy). Landslides 11, 43-54.

Casagli, N., Catani, F., Del Ventisette, C., Luzi, G., 2010. Monitoring, prediction, and early warning using ground-based radar interferometry. Landslides 7, 291-301.

Chelli, A., Mandrone, G., Truffelli, G., 2006. Field investigations and monitoring as tools for modelling the Rossena castle landslide (Northern Apennines, Italy). Landslides 3, 252-259.

Crosta, G.B., Chen, H., Lee, C.F., 2004. Replay of the 1987 Val Pola Landslide, Italian Alps. Geomorphology 60, 127-146.

Crosta, G.B., Chen, H., Frattini, P., 2006. Forecasting hazard scenarios and implications for the evaluation of countermeasure efficiency for large debris avalanches. Eng. Geol. 83, 236-253.

Crosta, G.B., di Prisco, C., Frattini, P., Frigerio, G., Castellanza, R., Agliardi, F., 2014. Chasing a complete understanding of the triggering mechanisms of a large rapidly evolving rockslide. Landslides 11, 747-764.

Del Ventisette, C., Casagli, N., Fortuny-Guasch, J., Tarchi, D., 2012. Ruinon landslide (Valfurva, Italy) activity in relation to rainfall by means of GBInSAR monitoring. Landslides 9, 497-509.

Della Seta, M., Martino, S., Scarascia Mugnozza, G., 2013. Quaternary sea-level change and slope instability in coastal areas: insights from the Vasto Landslide (Adriatic coast, central Italy). Geomorphology 201, 462-478.

Dymond, J.R., De Rose, R.C., 2011. Modelling landscape evolution in the Waipaoa catchment, New Zealand - a phenomenological approach. Geomorphology 132, 29-34.

Forcella, F., Rossi, P.M., 1987. Le deformazioni di versante presenti nel territorio di Fuipiano Imagna (Prealpi bergamasche). Bollettino della Società Geologica Italiana 106, 281-291 (In Italian).

Goodchild, M.F., 2011. Scale in GIS: an overview. Geomorphology 130, 5-9.

Hoek, E., Brown, E.T., 1997. Practical estimates or rock mass strength. Int. J. Rock Mech. Min. 34, 1165-1186.

Hoek, E., Marinos, P., Benissi, M., 1998. Applicability of the Geological Strength Index (GSI) classification for very weak and sheared rock masses. The case of the Athens Schist Formation. Bull. Eng. Geol. Env. 57, 151-160.

Huang, Y., Ye, W.M., Chen, Z.C., 2009. Seismic response analysis of the deep saturated soil deposits in Shanghai. Environ. Geol. 56, 1163-1169. 
Huang, R., 2012. Mechanisms of large-scale landslides in China. Bull. Eng. Geol. Env. 71, 161-170.

Intrieri, E., Gigli, G., Casagli, N., Nadim, F., 2013. Brief communication “Landslide Early Warning System: toolbox and general concepts". Nat. Hazard. Earth Syst. Sci. 13, 85-90.

Itasca, C.G., 2007. 3DEC Version 4.1 User's Guide. Minneapolis, Minnesota USA.

Jadoul, F., Gaetani, M., 1986. L'assetto strutturale del settore lariano centro-meridionale. Mem. Soc. Geol. It. 32, 123-131 (In Italian).

Kerry, R., Oliver, M.A., 2011. Soil geomorphology: identifying relations between the scale of spatial variation and soil processes using the variogram. Geomorphology 130, 40-54.

Kilburn, C.R.J., Petley, D.N., 2003. Forecasting giant, catastrophic slope collapse: lessons from Vajont, Northern Italy. Geomorphology 54, 21-32.

Lebourg, T., Binet, S., Tric, E., Jomard, H., El Bedoui, S., 2005. Geophysical survey to estimate the 3D sliding surface and the $4 \mathrm{D}$ evolution of the water pressure on part of a deep-seated landslide. Terra Nova 17, 399-406.

Lin, J.S., Ku, C.Y., 2005. Two-scale modeling of jointed rock masses. Int. J. Rock Mech. Min. $43,426-436$.

Longoni, L., Arosio, D., Scaioni, M., Papini, M., Zanzi, L., Roncella, R., Brambilla, D., 2012. Surface and subsurface non-invasive investigations to improve the characterization of a fractured rock mass. J. Geophys. Eng. 9, 461-472.

Longoni, L., Papini, M., Arosio, D., Zanzi, L., Brambilla, D., 2014. A new geological model for Spriana landslide. Bull. Eng. Geol. Env. 73, 959-970.

Marcato, G., Mantovani, M., Pasuto, A., Zabuski, L., Borgatti, L., 2012. Monitoring, numerical modelling and hazard mitigation of the Moscardo landslide (Eastern Italian Alps). Eng. Geol. 128, 95-107.

Marinos, P., Hoek, E., 2000. GSI - a geologically friendly tool for rock mass strength estimation. Proc. GeoEng2000 Conference, Melbourne, pp. 1422-1442.

Mazzanti, P., Bozzano, F., Cipriani, I., Prestininzi, A., 2015. New insights into the temporal prediction of landslides by a terrestrial SAR interferometry monitoring case study. Landslides 12, 55-68.

Moro, M., Saroli, M., Gori, S., Falcucci, E., Galadini, F., Messina, P., 2012. The interaction between active normal faulting and large scale gravitational mass movements revealed by paleoseismological techniques: a case study from central Italy. Geomorphology 151-152, 164-174.
Ning, Y.J., An, X.M., Ma, G.W., 2011. Footwall slope stability analysis with the numerica manifold method. Int. J. Rock Mech. Min. 48, 964-975.

Panizzo, A., De Girolamo, P., Di Risio, M., Maistri, A., Petaccia, A., 2005. Great landslide events in Italian artificial reservoirs. Nat. Hazards Earth Syst. Sci. 5, 733-740.

Pieraccini, M., Casagli, N., Luzi, G., Tarchi, D., Mecatti, D., Noferini, L., Atzeni, C., 2002. Landslide monitoring by ground-based radar interferometry: a field test in Valdarno (Italy). Int. J. Remote Sens. 24, 1385-1391.

Pirulli, M., Mangeney, A., 2008. Results of back-analysis of the propagation of rock avalanches as a function of the assumed rheology. Rock Mech. Rock. Eng. 41, 59-84.

Rocscience, 2007. RocLab User's Guide. Rocscience Inc, Toronto. 25 pp. Available free from www.rocscience.com.

Savazzi, G., 2005. Studio Geologico del versante in sinistra idrografica del torrente Varrone. Tratto: Centrale idroelettrica - viadotto SP67 - area Ecologica. Technical report unpublished. (In Italian)

Schönborn, G., 1992. Alpine tectonics and kinematic models of the central Southern Alps. Mem. Sci. Geol. 44, 229-393.

Schumm, S.A., Lichty, R.W., 1965. Time, space and causality in geomorphology. Am. J. Sci $263,110-119$

Smith, B.J., 1996. Scale problems in the interpretation of urban stone decay. In: Smith, B.J. Warke, P.A. (Eds.), Processes of Urban Stone Decay. Donhead, Shaftesbury, pp. 3-18.

Tibaldi, A., Rovida, A., Corazzato, C., 2004. A giant deep-seated slope deformation in the Italian Alps studied by paleoseismological and morphometric techniques. Geomorphology 58, 27-47.

Viles, H.A., 2001. Scale issues in weathering studies. Geomorphology 41, 63-71.

Viles, H.A., Moses, C.A., 1998. Weathering nanomorphologies: their experimental production and use as indicators of carbonate stone decay. Q.J. Eng. Geol. 31, 347-357.

Warke, P.A., McKinley, J.M., 2011. Scale issues in geomorphology. Geomorphology 130 $1-4$.

Yan, Y., Wang, S., Chen, J., 2011. Spatial patterns of scale effect on specific sediment yield in the Yangtze River basin. Geomorphology 130, 29-39.

Zengchao, F., Yangsheng, Z., Dong, Z., 2009. Investigating the scale effects in strength of fractured rock mass. Chaos Solition Fract. 41, 2377-2386.

Zhang, Q., Zhu, H., Zhang, L., Ding, X., 2011. Study of scale effect on intact rock strength using particle flow modeling. Int. J. Rock Mech. Min. 48, 1320-1328. 